\title{
Pedagogical possibilities of tourist and local history activities
}

\author{
Arman Demeuov ${ }^{1, *}$, Ordenbek Mazbayev ${ }^{2}$, Gulbanu Aukenova ${ }^{3}$, Ihor Kholoshyn ${ }^{4}$, and Iryna Varfolomyeyeva $^{4}$ \\ ${ }^{1}$ Abai Kazakh National Pedagogical University, 13 Dostyk Ave., Almaty, 050010, Republic of Kazakhstan \\ ${ }^{2}$ L. N. Gumilyov Eurasian National University, 2 Satpayev Str., Nur-Sultan, 010008, Republic of Kazakhstan \\ ${ }^{3}$ M. Bazarbayev School-gymnasium № 138, 26a, Koktem-1, Almaty, 050040, Kazakhstan \\ ${ }^{4}$ Kryvyi Rih State Pedagogical University, 54, Gagarina Ave., Kryvyi Rih, 50086, Ukraine
}

\begin{abstract}
In the new socio-economic conditions in the education system, forms of organization of tourist and local history activities are developing, which are based on traditions, experience of extracurricular and extracurricular work, taking into account the changes that have occurred in the country. Life requires that the tasks facing educational institutions are resolved quickly and have not just any solution, but one that optimizes the pedagogical process. At the same time, these requirements come into conflict with the state of the education system, the limited ability of most parents to create conditions for the full development of the child. The tasks facing the education system can be implemented in tourism and local history activities. The main task is to create the necessary conditions for the comprehensive development of the child's personality, his social adaptation in the process of participation in various types of tourist and local history activities. However, the school teacher is not ready to organize and conduct tourist and local history activities at school, as he is not professionally prepared for this activity. Questions of the organization, forms and methods of teacher training for the organization of tourist and local history activities are practically not reflected in the educational and methodological literature. There are no scientific studies that would allow us to effectively solve the pedagogical tasks of preparing the organizers of tourist and local history activities in the school.
\end{abstract}

\section{Introduction}

Pedagogically correct organized and structured tourist and local history work allows the teacher to implement the local history principle of teaching the subject. Collection and accumulation of local history material for use in the classroom, as a rule, is carried out in hikes and excursions, in the process of search work. Local history is closely related to the development of the basics of science, with the practical application of the basics of geography, biology, mathematics, and other subjects. Contributing to the acquisition of knowledge about the phenomena of the environment and life on the material of the local region. It is the most rational means of learning the general laws of nature by introducing students to the basics of production, makes it possible to link theory with practice, helps to develop practical skills. Local history contributes to the deepening of inter-subject relations in the educational process. For the first time in Kazakhstan, the training of geography teachers and organizers of tourist and local history work has been started since 1987 [1].

The use of local material in the process of perception and comprehension of knowledge helps to resolve the pedagogical tasks of the teacher: its use enriches the content of the teacher's explanation, gives it a specific character, and promotes education in the minds of students the concepts as the answer to new questions for which previous knowledge is not enough; the use of local material depending on lesson plans, changes the relationship between teacher and students.

The involvement of local history material in the process of transferring new knowledge creates a favorable problem situation when students come to a conclusion based on known facts, compare a number of scientific facts and phenomena with the facts of the environment, have the opportunity to critically comprehend and perform independent work.

During the study of local lore, schoolchildren learn the peculiarities of their own character, such important personality traits as mutual assistance, mutual assistance, responsiveness, responsibility, discipline, and tolerance are formed in them. In the course of the implementation of the collective form of activity, students develop a moral consciousness and an idea of the system of norms of moral behavior. So local history activity can act as a means of implementing the tasks of moral education.

In the process of tourist and local history activities, pedagogical directed influence, as a result of systematic and purposeful educational work, positive experience of behavior is accumulated, while favorable conditions are created for the formation of moral qualities of the child's personality. Tourism and local history in their modern understanding are physical development, health improvement and knowledge of the surrounding reality, the formation of valuable spiritual qualities of the individual [2].

\footnotetext{
*Corresponding author: arman_demeuov@mail.ru
} 
The education of such moral qualities as a sense of duty, responsibility for the assigned task, diligence, commitment, initiative, independence, contributes to the performance of permanent and temporary official duties by young tourists - commander, guide, treasurer, caretaker, kitchen attendant, etc. Mastering these skills also contributes to the formation of a conscious attitude to work, helps in choosing a profession.

Performing local history tasks on the route, constantly being in the natural environment, communicating with the local population, getting acquainted with the monuments of nature, history and culture contribute to the education of spiritual and moral qualities, patriotism. Thus, a system of tourist and local history activities was created.

In this article, we offer only one of the models of the tourist and local history cycle for students "GeographyTourism", where the whole process is shown in the diagram.

The first course - field practice in topography, geology, botany, meteorology.

The second course year-practical training in zoology, cartography, soil geography, hydrology and geomorphology.

Third year - performing the practice according to the Figure 1.

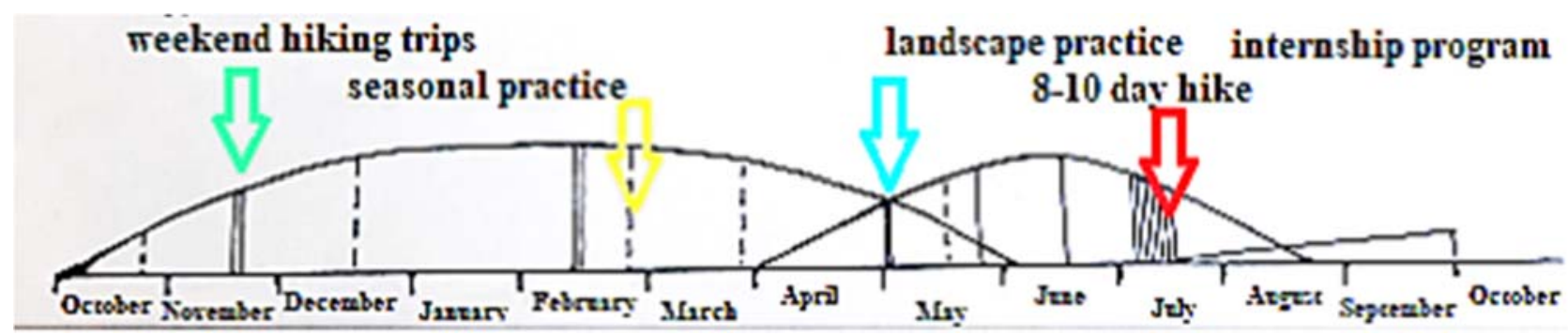

Fig. 1. Tourist and local history cycle for students of the Faculty of Natural Geography.

A. Special training "Big cycle" - instructive and methodical, economic, tourist and local history and physical training.

B. Small cycle. Practical work on the ground, improvement of tourist equipment and tactics. There is a special course on tourist and local history work at the school. Visiting schools and extracurricular institutions.

The fourth year - pedagogical practice at school (tourist and local history work in educational institutions).

Pedagogical universities using this model can prepare future geography teachers for the TLhA.

The novelty of the research is the application of this approach to the educational process at the university.

Using the model of interpretation, we focus on dual education, there is a practice-oriented approach. Students understand, are able and know the importance of tourist and local history work. [1]

Tourism and local history activities (TLhA) are an important means of improving the health and physical development of students. With the current unfavorable ecological state of cities and towns, high noise levels and other traumatic factors, as well as a significant time spent by children in closed rooms, a one-day or two-day hiking trip is an effective means of improving health and preventing diseases. Tourist trips, tourist competitions held in nature, distract them from strenuous educational activities, relieve stress and tension. The days spent in the fresh air give the children a powerful charge of cheerfulness and energy, allow them to work at school with creative enthusiasm and good mood. After a pedagogically well-organized hike, the teenager feels physically well and calm for several days. All this contributes to improving the quality of the educational process [3].
Visiting nature reserves and national parks is particularly popular in Canada, Kenya, the United States and China.

The common distinguishing features of European children's and youth tourism centers are a rich excursion and educational program with a wide range of sports and wellness services. In educational institutions in England, France, Germany, Austria and other countries, when studying individual subjects, teachers use walks and trips to nature in their work with students. Such methods allow students to acquire and maximize the need for knowledge, creativity, and self-determination personally and professionally. Youth tourism has become an integral part of the lifestyle of the younger generation in Germany. A wide network of youth tourist bases within Germany itself (more than 600 youth bases and 400 homes for young nature lovers) is provided for the services of young people, whose stay is very inexpensive for young residents of Germany. In Japan, during the school holidays, students go out to learn various folk crafts. Such excursions, on the one hand, foster respect for work, expand the understanding of the economic potential of the country. On the other hand, such trips can have an important utilitarian purpose - to help with the choice of a future specialty [4].

In Kazakhstan, tourism and local history activities are becoming a mass movement of the younger generation, parents and the pedagogical community in order to learn about the environment and through tourism. The state network of children's institutions of additional education of tourist and local history profile in Kazakhstan began to form in the 60 s of the XX century. During the years of independence, the education system of the Republic of Kazakhstan has developed and operates a system of tourist and local history work. 
Over the past decades, there has been a positive trend in the development of tourism and local history (2004-9 stations, 2019-37 stations).

More than 800 thousand children and teenagers participate in the implementation of such programs of the tourist and local history movement of students as "Atameken", "Bolashak", "Zhasurpak", "Shugyla", "Tugan elge tagzym" and others. Within the framework of the tourist and local history expedition of schoolchildren "Menin Otanym-Kazakhstan", dozens of hiking, skiing, water, cycling trips, expeditions and excursions are held annually, in which thousands of young tourists and their adult mentors participate. Every year, more than 1,300 specialized yurt and tent camps are organized in the republic, where 140 thousand children have a rest and get tourist skills [5].

In the process of tourist and local history activities, pedagogical directed influence, as a result of systematic and purposeful educational work, positive experience of behavior is accumulated, while favorable conditions are created for the formation of the moral qualities of the child's personality. First of all, these are the qualities that are brought up as part of a tourist group that exists in an autonomous mode-collectivism, responsibility and mutual assistance.

The authors have conducted experimental studies on the possibility of TLhA for 30 years. The result is the training of teachers-organizers on the basis of geographical education in a pedagogical university.

\section{Results and discussion}

Currently, 37 stations and centers of young tourists-local historians carry out tourist and local history educational activities in the Republic, 23529 schoolchildren are engaged in them. Between the ages of 6 and 18, 651,409 students are engaged in palaces and kindergartens, and 33988 students are engaged in tourist and local clubs and school associations. In general, 57517 children are covered by tourist and local lore directions, which is $1.96 \%$ of the total number of schoolchildren in 2018 (Figure 2).

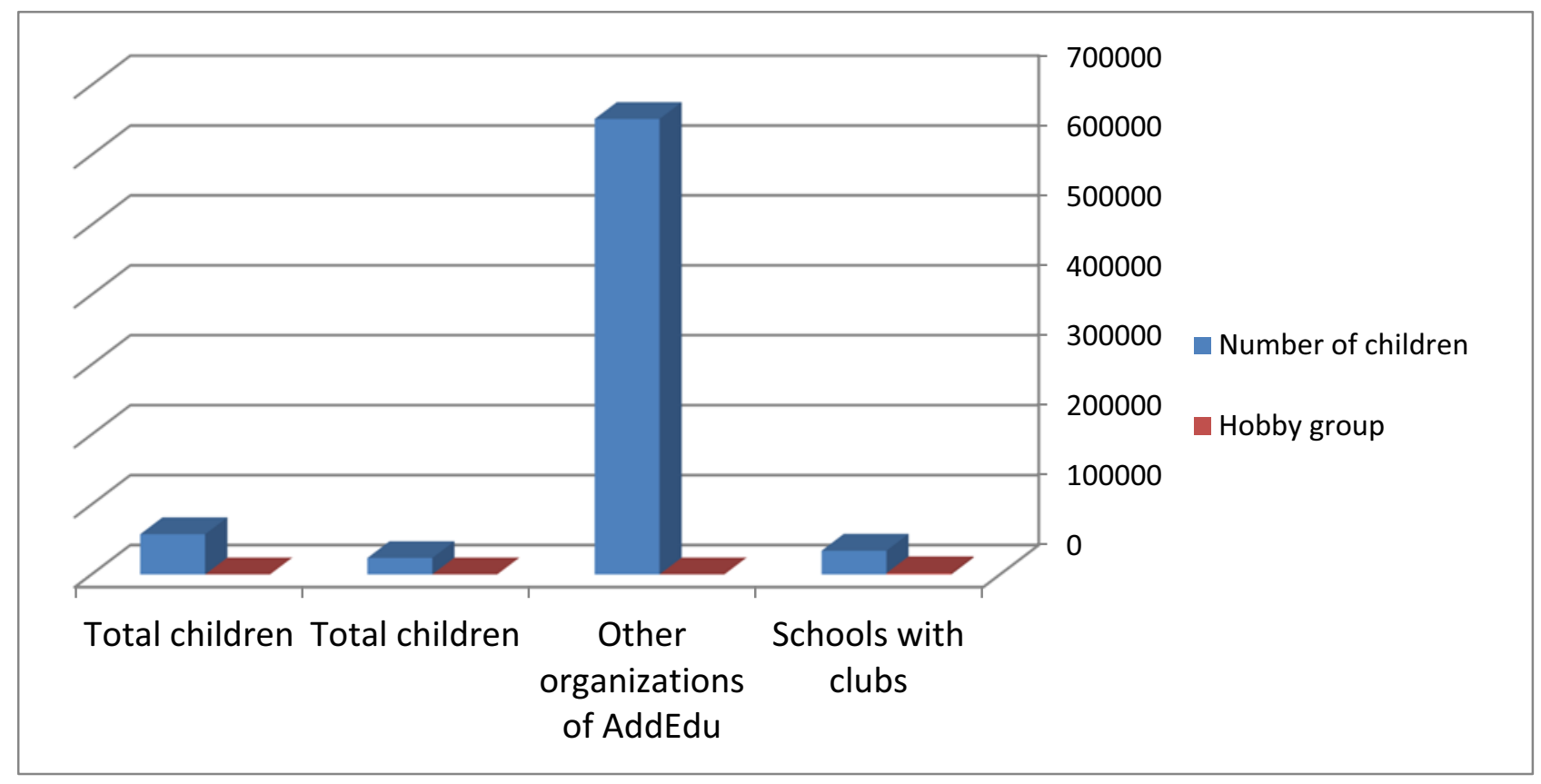

Fig. 2. The number of children employed in tourist and local history circles.

It is well known that with scientific, technical and social progress, the need for a person to assimilate a large amount of diverse information, quickly update knowledge, and improve skills increases. In these conditions, the role of tourist and local history activities, which integrates all the main pedagogical processes, is sharply increasing.

At this time, as a result of the research, the specialty "Geography - Tourism" was opened in the Republic of Kazakhstan, where the methodology of preparing future teachers for the leadership of the TCD of schoolchildren was tested. Similar work is being carried out at the Kryvyi Rih State Pedagogical University, where there is a specialty "Geography. Tourist and local history work".
The relevance of the development of children's and youth tourism is due to the fact that it allows you to solve many other problems, and one of them is hypodynamia a sedentary lifestyle, since the current younger generation lives in the era of computerization, modernization of technocracy.

Research scientists confirm the fact that as a result of the achievements of scientific and technical progress, computerization in all spheres of human activity has increased the number of cases of students, the amount of stress and disruptions in learning and behavior as a result of prealablement, insufficient exposure to fresh air, improper organization of leisure and recreation. After all, human health is closely related to the effects of the natural environment on the body and therefore tourism is the best 
way to solve this problem, which, unlike a variety of sports programs, has all the necessary natural components for health. This is communication with nature, a change of environment, psychological relief, and most importantly physical activity. Tourism is easy to organize, does not need specially equipped halls and platforms. The best sports ground was and still is nature! It is available for people of any age, is a feasible sport, because the load in it is well dosed with rest, and at the heart of ordinary walking. Being one of the most popular sports, it contributes to the education of a healthy and seasoned person, enriches the spiritual life neither in words, but in deeds, cultivates love for the native land. And in order for Kazakhstanis to love their land, it is necessary to instill this love from childhood. Most of all, this is facilitated by hikes, expeditions and trips, in which students have the opportunity to get acquainted with local attractions, with the past and present of their native land, with the traditions and customs of their people, to study the cultural heritage of their ancestors, conducting search activities.

In the educational organizations of the republic there are 7,668 deputy school directors for educational work, 18,402 teachers of additional education, including 851 teachers of tourism and local lore (698 of them with higher pedagogical education; 42 with higher professional education, 84 with secondary special pedagogical education and 27 with secondary special professional education (Figure 3) [6]. Tourist and local history activity is a pedagogical system, in the design of which a model of the system of continuous tourist and local history education was developed.

Engaging in various types of tourism since childhood allows you to cultivate a sense of citizenship, tourist culture and develops the ability to perceive the ideology of hospitality as a national idea, with the implementation of which it is possible to really develop tourism as an effective sector of the economy, ensuring sustainable development of the state with minimal consequences for nature and society [7].

\section{Total teachers of the tourist and local history direction \\ with higher pedagogical education}

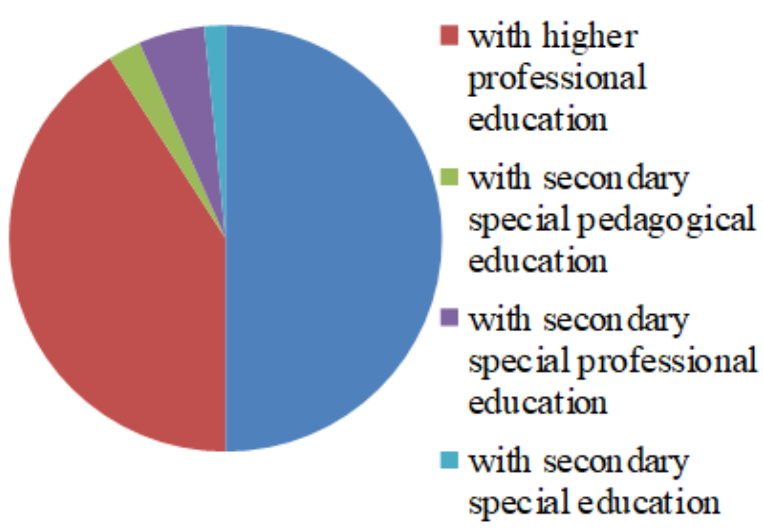

Fig. 3. Number of teachers of tourism and local lore in the Republic of Kazakhstan.
The developed tourist and local history activity is a pedagogical system, in the design of which the model of the system of continuous tourist and local history education is used.

The model of the system of continuous tourism and local history education (SCTLE) is a system of interrelated elements aimed at ensuring the main goal of continuous tourism and local history education-the formation of a harmonious personality and a healthy lifestyle.

SCTLE consists of four main stages of education: kindergarten, school education, additional education, vocational schools and universities. For each stage, goals and objectives are defined according to three parameters: training, education and development.

Kindergarten is the initial stage in the system of continuous tourism and local history education. The main tasks in the field of preschool education are:

- protection and promotion of children's health;

- mental development, physical, moral, aesthetic, environmental, economic, labor education;

- strengthening the role of the family in the upbringing of children.

During this period, children are laid the starting tourist skills, the basics of ecological culture, they receive initial information about their native land, the initial concepts of a healthy lifestyle.

The main tasks of the current stage of development of school education are:

- education for all-orientation of educational programs to high-quality education, upbringing and development of all children;

- the development of creative, spiritual and physical abilities of the individual, the formation of strong foundations of morality and a healthy lifestyle;

- education of a citizen, formation of a system of values and relations corresponding to a multinational society, Kazakhstan's patriotism; formation of a person with a rich spiritual, social and moral potential, capable of perceiving and developing national and world achievements in all spheres of life (fig. 4).

At the school stage of training, children undergo primary and secondary tourist training, learn the culture of behavior in nature, acquire the skills of local lore, research search and scientific design, join a healthy lifestyle, receive comprehensive education, pre-profile and profile training.

An integral part of continuing education and education is additional education, which is implemented on the basis of extracurricular organizations.

The purpose of the modern system of additional education is to create conditions for the formation of a versatile personality, including both modern (initiative, sociability, adequate adaptability, flexibility of behavior, mobility, leadership, organizational qualities, sociopsychological competence) and moral qualities (spirituality, sensitivity, attentiveness, honesty, responsibility, patriotism, tolerance, aesthetics).

The main tasks of additional education are defined:

- involvement of groups of student youth in the process of continuous education, familiarization with the achievements of national culture and sports; 
- $\quad$ stimulation of diverse harmonious development, creativity and activity;

organization of unregulated social communication, rational recreation and entertainment, adaptation to life in society.
Studying in clubs and sections of organizations of additional education, children have the opportunity to study local history, learn the traditions and rituals of their native land, improve and improve tourist skills, learn the basics of ecological culture.

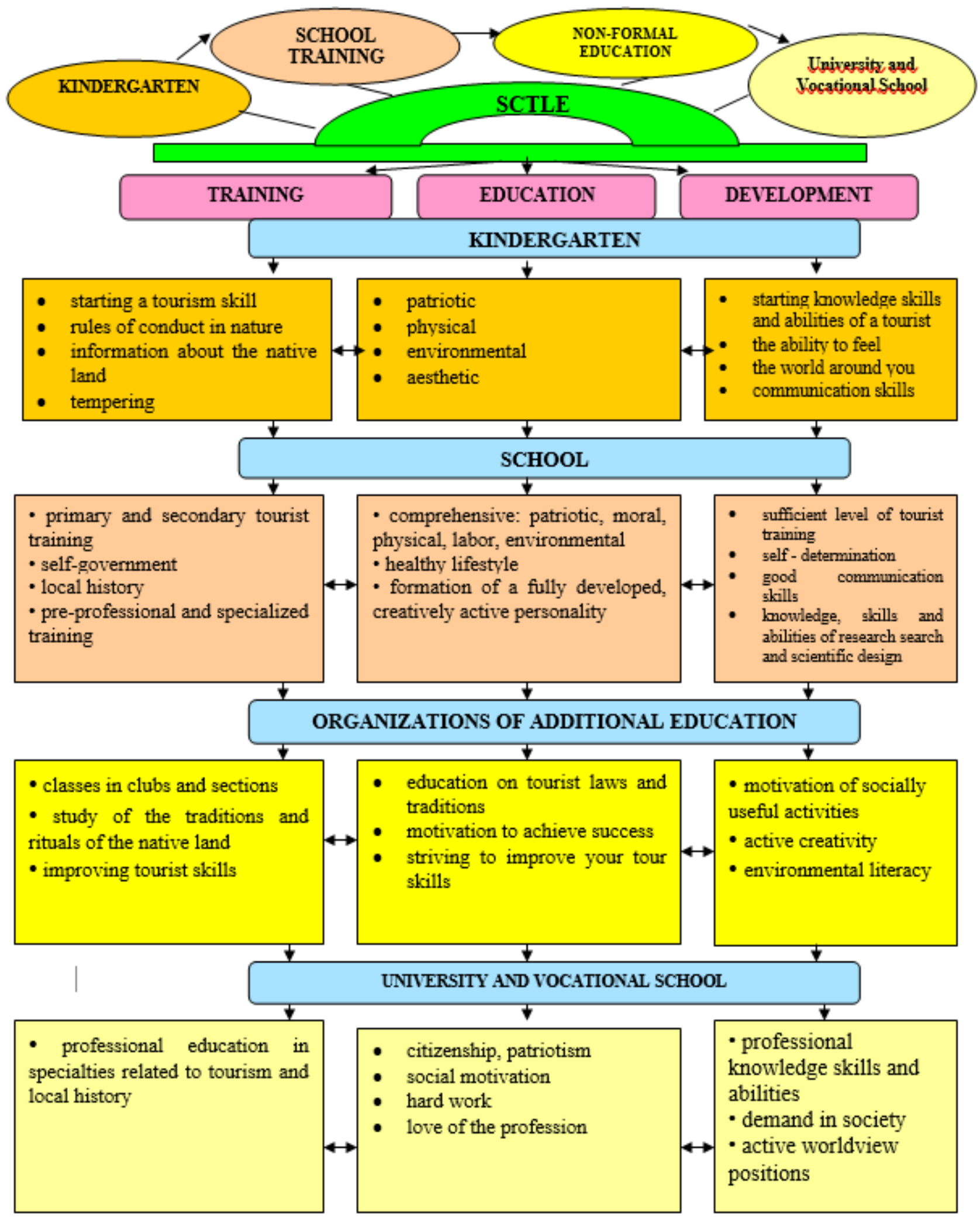

Fig. 4. The system of continuous tourist and local history education (SCTLE) [3]. 
At the stage of professional education in universities and vocational schools, students receive specialization in professions related to tourism and local history. The purpose of education at this stage is to provide conditions for the development of professional and social adaptation of the future specialist, the formation of a multicultural, humane and moral, physically healthy, highly intelligent, competitive, and therefore creatively developed holistic personality., able to independently formulate problems and practically solve them from high civil positions based on the use of national traditions and the latest achievements of world experience.

An important element of the professional training of a future teacher of geography and organizers of tourism and local history work at school can be the introduction of a special course "Organization of local history work at school" into the training system. The main tasks of this course are students awareness of the importance of tourism and local history work with schoolchildren, students mastery of various methods of studying their native land and readiness for local history and tourism work with students of different age groups. An important component of attracting students to tourism and local history work is their participation in educational excursions and tourist trips.

It is important, at the same time, to attract students to participate in excursions and hikes of various types: object-based (excursions and hikes to certain geographical objects studied in higher education); methodical (excursions and hikes on which students develop the ability to organize and conduct various tourist and local history events at school and out-of-school educational institution) and product (excursions and hikes that a student is able to develop as a finished tourist product that goes beyond the school curriculum, having an age limit) [8].

In the preparation of organizers of tourist and local history work at school, in our opinion, it is necessary to adhere to certain pedagogical conditions identified by O.V. Bondarenko:

- providing the goals of preparation for local history work of personal meaning;

stimulation of positive motivation of students in mastering generalized local lore knowledge and skills to use them in solving problem situations and cognitive tasks activation of students;

activity on the basis of personality-oriented and imitation-game approaches;

a variety of forms and methods of local lore work with the provision of future teachers the freedom to choose ways to solve educational problems and situations of success [9].

Based on a comprehensive approach to modeling continuous tourism and local history education, we can identify the main pedagogical conditions for improving its effectiveness: the implementation of a systematic approach in tourism and local history activities; inclusion of students in various types of TLhA through ensuring the unity of educational and educational work; training of teachers to solve problems and implement TLhA.

In order to identify the effectiveness of the proposed model, the search and selection of indicators of all types of education of the child's personality was carried out. The following indicators of types of education were determined:

- moral-love for the Motherland, respect for state symbols, internationalism, tolerance, respect for the traditions and customs of the people, citizenship;

physical - starting tourist knowledge, skills and abilities (KSA), strengthening of the musculoskeletal system, lung development, endurance;

labor - conscientiousness in the execution of labor orders, the manifestation of personal initiative in the performance of duties;

ecological - love of nature, knowledge of the rules of behavior in nature, understanding of the need for environmental protection;

aesthetic - the development of aesthetic taste, the ability to observe nature and enjoy the beautiful, the ability to display what you see in creative works.

The indicators of all types of personal education are measured by standard diagnostic tasks developed according to the levels of complexity, taking into account age characteristics, on the basis of which the level of training of pupils (LTP in \%) was determined at the stages of ascertaining and forming experiments in the control and experimental groups. High (when reaching 100-81\%), medium (80-61\%), and low (60-40\%) levels were determined to determine LTP.

CG-control group - a part of the group that receives standard tourist and regional knowledge, its participants participate in fragmentary events of the TLhA.

EG-experimental group - part of the group engaged in specialized programs [10].

The competence approach in education originated in the scientific and journalistic literature in the late 1980s. To date, there is a multivariance in the definition of the terms "competence", "competence", which are used with the related concepts of "professionalism", "qualification", "education", etc. Most researchers hold the view that competence is an opportunity not just to have knowledge, but rather to potentially be ready to solve problems with knowledge.

The essential features of competence include the level determined by a combination of the following criteria:

- $\quad$ the level of assimilation of knowledge and skills (quality of knowledge and skills); the range and breadth of knowledge and skills;

- ability to perform special tasks;

- $\quad$ ability to rationally organize and plan your work;

- ability to use knowledge in non-standard situations (functional literacy).

Competence is a parameter of a social role, which in personal terms manifests itself as competence, the person's compliance with the place and time occupied; the ability to carry out activities in accordance with social requirements and expectations.

Tourist and local lore competencies are a parameter of a person's social experience that determines tourist and local lore knowledge, skills and abilities in accordance with the time, place, and surrounding society [11]. The formation of tourist and local history competencies of the younger generation of children provides for the acquisition of behavioral and survival skills in nature, the 
development of personal qualities (sociability, leadership, strong-willed qualities), motivates self-realization, selfknowledge, cooperation, and a healthy lifestyle.

We consider a comprehensive approach to the education of a well-developed personality in SCTLE at the preschool and school levels along two verticals that reflect all types and forms of TLhA.

During the implementation of the model of the system of continuous tourist and local history education at the stages of preschool and school education, organizational and pedagogical conditions were provided for all types of education: moral, patriotic, physical, labor, environmental, aesthetic.

We consider organizational and pedagogical conditions as a set of elements that contribute to the comprehensive development of the individual.

Organizational conditions are forms of organization and activity of preschoolers and schoolchildren. We refer the content, methods and technologies of the educational process organization to the pedagogical conditions.

We are confident that the measures taken will make it possible to use the entire arsenal of youth and youth tourism to educate the country's comprehensively developed younger generation, form a tourist culture among Kazakhstan's youth and commit to a healthy lifestyle. Tourism and local history have always been a powerful tool in the system of education and upbringing of the younger generation, the formation of a healthy lifestyle, the organization of recreation, leisure and restoration of spiritual and physical strength. After all, Ya. A. Komensky in his writings wrote: "Education is a process of life, not a preparation for the future life» [12].

TLhA in a school develops if it has a tourist organizer from among the teachers. When appointing a school tourism organizer, the school administration should be guided by the candidate's presence of the following important indicators:

- the strength of belief in the great importance of tourism for the school, in the need for it;

- the nature of views on the essence of children's tourism, i.e. the position, the candidate's approach to tourism and local history from the point of view of the tasks of the school, pedagogy;

- the level of tourist qualifications-personal experience of hiking, knowledge of tourism techniques, knowledge of the methods of organizing this work;

- such personal qualities as perseverance, perseverance, but also, at the same time, flexibility, the ability to correctly assess the moment, trend and prospect of the case.

The tourist organizer of the school needs to solve the problem so that, over time, a small but strong tourist asset will form around him from among teachers, parents, students, and production workers. The school needs a group of 3-5 people who are ardent supporters of tourism, who are truly passionate about this form of educational work with children. A school with a developed TLhA system is always distinguished by a large, friendly and strong asset of tourists-schoolchildren, first of all-high school students. As practice shows, in such a school, each class has its own class tour organizer, and the school-wide tourist self-government is implemented through the Headquarters or the Tourism Board.

The role of the student asset, its forms and structure in modern pedagogical science are practically not developed. However, it is possible to distinguish two completely independent factors, two separate, but interrelated goals that are inherent in the existence of a children's tourist asset:

- practical benefits for the organization of tourist and local history work in the school, which gives the labor contribution of the children's assets to the organizational work;

- pedagogical benefits, which gives the work of children in the education of their own social activity.

The activity of the school tourist asset gives a great pedagogical return: the children work for pedagogy and at the same time, working in the field of education, they themselves fall under the influence of the educational process. In this way, through the TLhA, an important task is solved: with the help of the children themselves, to conduct the pedagogical process in cooperation with them, without alienating them from "adult" affairs. Here we have a moment of cooperation in the pedagogy of the teacher with the students, a connection so far in the miniature of the state and public administration of school affairs.

The concept of a tourist asset can be classified according to the following parameters: by the nature of the activity; by the legal type of relations to the activity; by the scale of the activity; by the profile of the activity (specialization); by the level of training; by the duration of the activity. At each stage of the development of the system of tourist and local history work, the school should have its own corresponding structure of the asset and its own content of its work, since the discrepancy between these components of the system creates unnecessary contradictions and leads to failures in the development of the system.

In order to establish a system of tourist and local history work in the school, much is needed, but most importantly-you need a teacher who is ready for a hike, who is able to properly organize and competently conduct a tourist trip with children. In universities, teachers are not trained to conduct tourist work, they are mainly taught the methods of teaching the subject and very little is taught about the necessary practical skills. Therefore, class teachers, in the vast majority, are not ready for a variety of extracurricular educational work with children and do not want to engage in an unfamiliar business, especially in such a peculiar direction as TLhA. It is not enough to teach a teacher only a variety of tourist technologies, it is still necessary to educate him, to instill a taste for tourism pedagogy-the direction of educational work.

In the end, you need to achieve the following three conditions:

- the teacher's awareness of the usefulness of tourism (hiking) for performing their professional tasks;

- the teacher's confidence in their ability to go hiking with children;

- the teacher's sense of comfort in hiking, based on the guaranteed provision of everything necessary for such activities. 
When planning work on tourist training, it is necessary: - to study the available personnel, to determine the positions of each employee to be trained, the level of his knowledge, i.e. to assess the degree of readiness of class teachers, teachers, educators to solve the tasks that are set at the first stage of the development of the TLHA system; - to determine the content, training programs, who to teach what, who to convince of what; - to outline specific forms, methods, methods, means of training; - to choose a leader, lecturers, instructors.

It is necessary to approach the tourist training of teachers in a differentiated way: first, to take into account the individual capabilities of each class teacher, and secondly, the needs of the school itself (children) in the development of the TLHA system. When organizing this work, it should be taken into account that school tourism is divided into two independent and interrelated parts mass and circle tourism. The development of the circle branch of tourism is possible if there is even one welltrained teacher in the school, whose work can be supported by invited part-time circle leaders. It is necessary to attach a young teacher to an experienced teacher-circle leader for individual training and internship, who in a few months will be able to lead the circles in the lower grades. This tandem is also useful because in a large multi-day hike with a group of students, there must be two adults-the head and his deputy. The main concern is the development of the "Mass Tourism" branch, which requires that all class teachers and educators have at least the most minimal training and experience in tourism - personal experience of hiking.

Therefore, the main task is to pass through the tourist training of teachers, without which it is impossible to improve the TLhA system in the school. According to the results of the study, it was found that the weakest link in the training of teachers, as a rule, is the pedagogy of tourism - the teacher's approaches to the content of hikes, goals, and methods.

The educational campaign is held in order to remove the teacher's fear of the campaign, before everything unusual, unusual, which is associated with the campaign and the accompanying pedagogical work. You can only be convinced of the benefits of a hike by participating in it. The hike should be carried out in good weather on a beautiful route, should not be difficult, and in the cognitive aspect very informative. Its program must necessarily include orientation on the terrain using a compass and a map, the most simple (for the first time) obstacles, acquaintance with nature and with a bright excursion object, bivouac breaking (choosing a place, making a fire, cooking, etc.). Important is the preparation of the campaign-the motivation for choosing the route, the distribution of hiking duties, questions of equipment and equipment.

In summing up the results, it is an important stage of the events held. For popularization, the most common and acceptable forms are lectures and seminars. The school should develop its own seminar program based on the existing ones and taking into account individual needs. It is necessary to plan a series of theoretical and practical classes with teachers per year and taking into account the prospects for the growth of tourist qualifications. The seminar on tourist work at school is the simplest option for training teachers, but its fruits are not too weighty, because it mainly takes place in the mode of studying theory. A more effective form of tourist training of teachers is a field seminar, which can be held on the basis of another school, the House of Creativity, the regional Syutur, the local history museum. Significant advantages in the organization of a productive educational process is such a form as a training camp, when participants for a day, for two or even for a longer period break away from the home environment and move to a certain place where they live and study all these days. According to the nature of the organization of the educational process, training camps are divided into a training camp-seminar and a training camp-hike. In the first case, the participants mainly listen to lectures, exchange experiences, and conduct practical exercises on the ground and indoors. In the second case, in addition to the short lecture part of the collection, a full-fledged tourist trip is held for one or two or more days, and at the end - an analysis of the results. A valuable form of systematic consulting assistance to teachers is a tourist corner, equipped in the recreation area of schools or in a special office of the school. The teacher should always have a self-service source of information on tourism and local history at hand. In the tourist corner there should be a map of the district, region, and surrounding areas of the city, a shelf with books and brochures, folders with methodological materials on various topics, forms of documents, tools for copying and working with maps, etc.The most important form of training teachers in tourism is the analysis of the practice of living specific tourist work. And if any of the above forms of training can be applied by choice, then the analysis of practice, the exchange of experience must necessarily be used in addition to all the others. It is necessary to fully draw pedagogical conclusions from the analysis of the work practice: to objectively reveal not only the results, but also the course of the pedagogical process in the campaigns, through the vision of which one can understand both what a friend has achieved and how he achieved it [6].

\section{Conclusions}

The peculiarity of the organization of training today is the fundamental issue of the organization of the educational process in educational institutions of all levels: from preschool to higher education. This primarily concerns the increase in such forms and methods of teaching that form key competencies, create conditions for development and the ability to make decisions on their own, to learn throughout life. In our opinion, the organization of continuous tourism and local lore education will make it possible to realize these goals. The model created and described in the paper demonstrates the step-by-step nature of educational work. Certain tasks make it possible to choose the most effective forms and methods of work for each level.

The peculiarities of the organization of tourism and local lore work at the stages of preschool, school and additional education should be mass character, the 
implementation of educational and educational goals, the acquisition of healthy lifestyle skills, the formation of a need for active knowledge of the world around. The organization of such activities should complicate and take into account the age characteristics of children. For example, in kindergarten, from walking to category hikes in high school. The results of tourist trips are used for the local history approach in the subjects of geography, biology, history, literature and a number of other subjects.

In higher educational institutions, the main task is to prepare students for planning and organizing tourism and local history work with children. Therefore, work at universities should be aimed at the formation of subjectspecific tourist and local history competence through a specially developed block of academic subjects (methods of organizing tourist and local history work, sports tourism techniques, methods of conducting educational excursions). The second, no less important part should be the acquisition of personal experience in organizing tourist activities. To do this, it is important to organize educational tourist, local history practices, hikes and excursions. Carrying out such work will create a strong motivation for future teachers and a willingness to organize tourist and local history work.

The conducted research confirms that tourist and local history work is a universal means of education and upbringing. And preparation for the management of the implementation of activities is necessary for future subject teachers.

\section{References}

1. O. Mazbaev, Dissertation, Alma-Ata, 1993.

2. A. Ryabov, Metodicheskiye rekomendatsii po organizatsii turistsko-krayevedcheskoy raboty $v$ obrazovatel'nom uchrezhdenii (Guidelines for organizing tourism and local lore work in an educational institution). (Nolinsk, 2018) p 46

3. G. Shayakhmetova, Vestnik MADUTK 1 97-122 (2015)

4. Second World Congress on Open Educational Resources, https://ru.unesco.org/events/vtoroyvsemirnyy-kongress-po-otkrytym-obrazovatelnymresursam Accessed: 07.02.2019

5. Yv. Nikitinsky at all, Vestnik MADUTK 2 29-66 (2015)

6. Reference material on the organization of children's and youth tourism in the Republic of Kazakhstan, ), (Astana, 2015) p 55 https://a1285830-28fb-4270$\underline{8 f 56-}$

0162e55e4975.filesusr.com/ugd/809cb6 d09726ac83 394febafcf0e4ee0fd0328.pdf

7. Yv. Nikitinsky, J. World of travel, 3 34-38 (2012)

8. O. Hanchuk, Pedahohika vyshchoyi ta seredn'oyi shkoly 43 16-21 (2014)

9. O. Bondarenko, Dissertation, Kryvyi Rih State Pedagogical University, 2009 http://elibrary.kdpu.edu.ua/handle/0564/1706

Accessed: 07.10.2020
10. T. Zhizdybaev, Shkolnyy turizm i krayevedeniye Respubliki Kazakhstan (School tourism and local history of the Republic of Kazakhstan) (Almaty, 2001) p 165

11. G. Shayakhmetova, M. Abenov, Organizatsiya turistsko-krayevedcheskikh meropriyatiy so studentami vo vremya letnego palatochnogo gorodka (Organization of tourist and local history activities with students during the summer tent camp), (Astana, 2015) p 56

12. A. Ayapbekova, Toponimy, sostavlyayushchiye geosistemy, Uchebnik (Toponyms that make up geosystems, Textbook), (Astana, "Turan-Astana", 2018), p 116 